\title{
The Role of Gene Polymorphisms in the Exacerbation and Prognosis of Chronic Obstructive Pulmonary Disease (Copd)
}

\author{
Eugenio Greco ${ }^{1 *}$ and Elio Stellitano ${ }^{2}$ \\ ${ }^{1}$ Fellow of the European Society of Cardiology, Italy \\ ${ }^{2} \mathrm{Head}$ of the Unit of Internal Medicine, Italy
}

Submission: August 09, 2018; Published: August 24, 2018

*Corresponding author: Eugenio Greco, Fellow of the European Society of Cardiology, Fuscaldo, Italy Email: eugeniodoc@hotmail.it

\section{Introduction}

Chronic Obstructive Pulmonary Disease (COPD) is a common disease that is characterized by persistent respiratory symptoms and airflow limitation, usually caused by exposure to noxious particles or gases; the most common symptoms are cough, dyspnea and sputum production; the main risk factor is tobacco smoking, but genetic abnormalities predispose individuals to develop it.

COPD is often associated with significant concomitant chronic diseases, which increase its morbidity and mortality, as cardiovascular disease, heart failure, ischemic heart disease, arrhythmias, peripheral vascular disease, lung cancer, metabolic syndrome and diabetes, osteoporosis, anxiety and depression, hypertension, gastroesophageal reflux, bronchiectasis, obstructive sleep apnea.

It is estimated that the number of CODP cases was 384 million in 2010 with 3 million deaths annually, with a rise over 4.5 million deaths annually by 2030 .

ABCD groups are now proposed to be derived exclusively from patient symptoms and their history of exacerbations; for each of the groups A to D, escalation strategies for pharmacologic treatments are proposed. Spirometry is required to establish a diagnosis of COPD if in individual over age 40 are present indicators which increase the probability of the diagnosis of COPD. [1]

\section{Genes and Copd}

The best-documented genetic risk factor is the severe hereditary deficiency of alpha-1 antitrypsin 26, an important serum protease inhibitor. Although alpha- 1 antitrypsin deficiency is only relevant for a small part of the world population, it is an example of gene interaction and environmental exposure leading to COPD [2].
Authors have confirmed that a first important step to assess the complexity of COPD is the development and validation of several multidimensional assessment indices, such as the BODE index (body mass index, FEV1, dyspnea, and exercise capacity), the ADO index (age, dyspnea, FEV1), and the DOSE index (dyspnea, FEV1, smoking status, and exacerbation frequency). All of them, however, are based on clinical and functional variables only, whereas it is well established that COPD is also a complex disease at the molecular and genetic levels; it is well known that only a percentage of smokers develop COPD, suggesting a genetically determined susceptibility for the disease. However, information at the genotype, molecular, cellular, and phenotype levels is important to understand and manage COPD [3].

\section{Gene polymorphisms}

Most respiratory diseases occur as a result of the complex interaction between individual genotype and environmental exposure. The study of some of the numerous gene polymorphisms studied in the genesis of COPD allows to formulate various hypotheses. Polymorphisms of cytochrome P450 (CYP) and matrix metalloproteinase: a risk factor for very severe COPD. Authors investigated whether polymorphisms of cytochrome P450 (CYP) and matrix metalloproteinase (MMP) are associated with the development and severity of chronic obstructive pulmonary disease (COPD). Genotypes of 184 patients with COPD and 212 controls were determined, and the results were:

a) The homozygous T allele of MMP-9 was significantly higher in patients with COPD than in controls $(14.7 \%$ vs. $7.5 \%)$.

b) No differences were observed in the frequency of polymorphic genotypes in CYP1A1, 1A2, MMP-1 and -3.

c) During combined analysis of these candidate genes, we found strong indicators for susceptibility to COPD (combined 
with homozygotes $* 2 \mathrm{~A}$ for CYP1A1 and T alleles of MMP-9 versus others $=3.3,95 \% \mathrm{CI} 1.2-8.6$ ).

d) The frequency of the homozygous *2A allele of CYP1A1 was significantly higher in very severe COPD $(\mathrm{P}<0.01)$. La frequenza della omozigosi.

e) Combinations of genetic variants including $* 2 \mathrm{~A}$ homozygotes of CYP1A1 and T alleles in MMP-9 are significant indicators for susceptibility to COPD.

f) Combinations of genetic variants including $* 2 \mathrm{~A}$ homozygotes of CYP1A1 and T alleles in MMP-9 are significant indicators for susceptibility to COPD.

g) The homozygous *2A allele of CYP1A1 is an independent risk factor for very severe COPD [4].

\section{Polymorphism of SIGLEC -14}

Some authors draw attention to the Siglec - 14, family of sialic acid binding lectins, which exerts a pro-inflammatory and antibacterial activity. The genes of origin of this family of proteins are grouped on chromosome 19q 13.3-4, a region inter alia adjacent to a susceptibility locus for the development of early COPD. The authors have observed that the absence of an allele of the protein-coding gene (siglec-14 null polymorphism) results in an immune response attenuated against pathogenic bacteria expressing sialic acid such as haemophilus influenzae not typable (nthi), frequently called in cause in the COPD exacerbations. The presence of this polymorphism, which causes the loss of the siglec-14 protein function, is associated with a reduced risk of exacerbations. During the evolution, Siglec-14 was necessary for a protection against bacterial infections; but today, with higher life expectancy, inducing a chronic inflammation can lead in the subjects with COPD to the appearance of a phenotype of frequent exacerbation. According to the authors, this phenotype not only causes the progression of COPD, but it can also be involved in the pathogenesis of the disease (since only the pathway of the tyrosine - phosphatase is activated by the pathogen with the result of a weak inflammatory response) [5].

\section{Conclusion}

a) Antibacterial but also pro-inflammatory molecules such as Siglec-14 would cause reiterated exacerbations of COPD; the excessive inflammatory response would trigger chronic local and systemic inflammation.

b) The identification by genetic analysis of the Siglec-14 null polymorphism could represent a new tool to identify the subjects at greatest risk of exacerbation of CODP

c) Attention should shift to the genetics side to identify patients at risk of developing exacerbations.

\section{References}

1. Vogelmeier CF, Criner GJ, Martinez FJ, Anzueto A (2017) Global Strategy for the Diagnosis, Management, and Prevention of Chronic Obstructive Lung Disease Report. GOLD Executive Summary. Am J Respir Crit Care Med 195(5): 557-582.

2. (1997) WHO meeting participans. Alpha 1-antitrypsin deficiency: memorandum from a WHO meeting. Bull World Health Organ; 75(5): 397-415.

3. Agusti A, Sobradillo P, Celli B (2011) Addressing the Complexity of Chronic Obstructive Pulmonary Disease. From Phenotypes and Biomarkers to Scale-Free Networks, Systems Biology, and P4 Medicine. Am J Respir Crit Care Med 183(9): 1129-1137.

4. Cheng SL, Yu CJ, Yang PC (2009) Genetic polymorphisms of cytochrome p450 and matrix metalloproteinase in chronic obstructive pulmonary disease. Biochem Genet 47(7-8): 591-601.

5. Angata T, Ishii T, Motegi T, Oka R, Taylor RE, et al. (2013) Loss of Siglec-14 reduces the risk of chronic obstructive pulmonary disease exacerbation. Cell Mol Life Sci 70(17): 3199-3210.

\begin{tabular}{|l|}
\hline \multicolumn{1}{|c|}{ Your next submission with Juniper Publishers } \\
will reach you the below assets \\
- Quality Editorial service \\
- Swift Peer Review \\
- Reprints availability \\
- E-prints Service \\
- Manuscript Podcast for convenient understanding \\
- Global attainment for your research \\
- Manuscript accessibility in different formats \\
( Pdf, E-pub, Full Text, Audio) \\
- Unceasing customer service \\
Track the below URL for one-step submission \\
https://juniperpublishers.com/online-submission.php
\end{tabular}

